\title{
Viabilidade espermática após a troca de plasma seminal entre machos suínos com diferente sensibilidade ao resfriamento
}

\section{Sperm viability after change of seminal plasma between boars with different chilling sensitivity}

\author{
Goreti Ranincheski dos Reis," Patrícia Schwarz, ${ }^{*}$ Mari Lourdes Bernardi, ${ }^{\star \star}$ Fernando Pandolfo Bortolozzo, ${ }^{*}$ Ivo Wentz
}

\begin{abstract}
Resumo
O objetivo deste estudo foi verificar um possível efeito do plasma seminal (PS) na sensibilidade espermática ao resfriamento, a partir da troca cruzada de PS, entre cachaços com diferente manutenção da motilidade (MOT) a $17^{\circ} \mathrm{C}$. Foram utilizados como doadores de sêmen cinco cachaços selecionados previamente, de um total de 30 machos, conforme a MOT do sêmen avaliada durante sete dias de armazenamento a $17^{\circ} \mathrm{C}$, e classificados como: menor (MES - MOT $360 \%$ após $144 \mathrm{~h}$ ) e maior sensibilidade ao resfriamento (MAS - MOT <60\% nas $72 \mathrm{~h}$ ). Ejaculados dos machos MAS e MES foram distribuídos em seis tratamentos, com cinco repetições cada. Nos tratamentos T1 e T3, o sêmen dos machos MES e MAS, respectivamente, foram processados de acordo com o protocolo convencional. Foi efetuada centrifugação ( $800 \mathrm{~g}$ por $10 \mathrm{~min}$ ) e adição do PS (10mL) homólogo para os espermatozóides MES e MAS, respectivamente, nos T2 e T4. Após a centrifugação, foi realizada a troca do PS, sendo que espermatozóides dos machos MES foram expostos ao PS dos machos MAS (T5) e o PS dos machos MES foi adicionado aos espermatożóides dos machos MAS (T6). As doses de sêmen, diluídas em BTS, contendo três bilhões de espermatozóides e distribuídas de acordo com os tratamentos descritos foram avaliadas durante sete dias de conservação. A MOT foi avaliada a cada $24 \mathrm{~h}$. Os percentuais de acrossomas normais (NAR) e de membranas íntegras (IM) foram avaliados nas 24, 72, 120 e 168h. Diferenças significativas ( $P=0,038)$ na MOT, entre os machos MES (T1) e MAS (T3), foram observadas após armazenamento de 48 horas. Em termos de IM, foi verificado um maior percentual $(P=0,027)$, para os machos MES, na avaliação efetuada nas 120 horas. Diferenças significativas $(P<0,01)$ no NAR, foram também verificadas, para os machos MAS, embora somente nas 72 horas, quando o ejaculado desses machos foi submetido à centrifugação e adição de PS homólogo ou heterólogo. Não foram observadas alterações na MOT e na IM, quando foi efetuada a troca de PS entre os machos MES e MAS. Os espermatozóides oriundos dos machos MAS apresentaram diminuição de $11 \%$ na MOT nas 24 horas, quando submetidos à centrifugação, ao passo que espermatozóides oriundos dos machos MES apresentaram diminuição de $16 \%$ na MOT $(P=0,054)$, porém somente nas 168 horas. Uma diminuição da IM, embora somente nas 168 horas, foi também observada, tanto para os machos MES como para os MAS $(P<0,01)$, quando o sêmen destes machos foi centrifugado e adicionado de PS homólogo ou heterólogo. A centrifugação, utilizada durante o processamento de troca do PS, entre machos com diferente sensibilidade ao resfriamento, tem efeitos deletérios sobre a motilidade e a integridade de membrana da célula espermática, sobretudo para os machos MAS. Não foi possível reverter a maior sensibilidade ao resfriamento de espermatozóides suínos, após a ejaculação, com a adição de $10 \%$ do PS de machos com sêmen de menor sensibilidade.
\end{abstract}

Palavras-chave: espermatozóide, motilidade, plasma seminal, resfriamento, suíno

\begin{abstract}
The objective of this study was to evaluate a possible effect of seminal plasma (PS) on sperm chilling sensitivity, through changing of PS, between boars with different maintenance of motility (MOT), at $17^{\circ} \mathrm{C}$. Five boars were selected in advance, from 30 boars, according to the maintenance of MOT evaluated during seven days of conservation at $17^{\circ} \mathrm{C}$, and the boars were classified in: low (MES - MOT ${ }^{3} 60 \%$ at $144 \mathrm{~h}$ ) and high (MAS - MOT $<60 \%$ at $72 \mathrm{~h}$ ) chilling sensitivity. Ejaculates of MAS and MES were distributed in six treatments, with five replications each one. In T1 and T3, semen from boars MES and MAS, respectively, were processed according to the conventional protocol. Centrifugation ( $800 \mathrm{~g}$ for $10 \mathrm{~min}$ ) was performed and homologous PS $(10 \mathrm{~mL}$ ) was added to sperm MES and MAS, respectively, in T2 and T4. After centrifugation, sperm from boars MES was exposed to PS from boars MAS (T5) and the PS of boars MES was added to sperm of boars MAS (T6). Doses of semen, diluted in BTS, with three billions of sperm and distributed according to the treatments described above were evaluated during seven days of conservation. Sperm motility was evaluated each $24 \mathrm{~h}$. The percentages of normal acrosomes (NAR) and intact membranes (IM) were evaluated at $24,72,120$ and $168 \mathrm{~h}$. Significant differences $(P=0.038)$ in MOT, between boars MES (T1) and MAS (T3), were observed after $48 \mathrm{~h}$ of storage. Boars MES had a higher percentual of $I M(P=0.027)$ at $120 \mathrm{~h}$. Significant decrease $(P<0.01)$ in NAR

\footnotetext{
* Setor de suínos, Faculdade de Veterinária da UFRGS, Av. Bento Gonçalves, 9090, CEP 91540-000. Porto Alegre, RS. E-mail: grreis@ hotmail.com - Autor para correspondência.

* Dept ${ }^{\circ}$ de Zootecnia, Faculdade de Agronomia da UFRGS, Av. Bento Gonçalves, 7712, CEP 91540-000. Porto Alegre, RS.
} 
was also verified for boars MAS, although only at $72 \mathrm{~h}$, when their semen was submitted to centrifugation and addition of PS homologous or heterologous. No alterations in MOT and in IM were observed when PS was changed between MES and MAS boars. Sperm from boars. MAS had a reduction of $11 \%$ in MOT $(P<0.005)$ already, at $24 \mathrm{~h}$, when it was submitted to centrifugation, while sperm from boars MES had a reduction of $16 \%$ in MOT $(P=0.054)$, only at $168 \mathrm{~h}$. Reduction of IM, although only at $168 \mathrm{~h}$, was also observed, for MES and MAS boars $(P<0.001)$, when semen was centrifuged and added of $P S$ homologous or heterologous. Centrifugation used during the processing for changing of PS, between boars with different chilling sensitivity, has deleterious effects on motility and membrane integrity of sperm, mainly to MAS boars. It was not possible to reverse the higher chilling sensitivity of ejaculated swine sperm, with the addition of seminal plasma of more resistant boars.

Keywords: chilling, motility, seminal plasma, spermatozoa, swine

\section{Introdução}

Embora os efeitos do plasma seminal (PS) sobre a função da célula espermática suína tenham sido amplamente estudados, os resultados ainda são contraditórios. Estudos têm mostrado que há um fator inibidor da motilidade no PS de suínos (Iwamoto et al., 1992; Kordan et al., 1998). Entretanto, uma melhora na motilidade tem sido observada com a adição de PS no diluente de espermatozóides descongelados (Guthrie, Maxwell e Johnson, 2000) ou sexados (Maxwell, Welch e Johnson, 1997). Também tem sido reportado como um efeito benéfico do PS o aumento na resistência do espermatozóide aos danos do choque térmico (Pursel, Johnson e Schulman, 1973; Berger e Clegg, 1985), embora a remoção ou não do PS; durante o processo do congelamento, não afete a viabilidade espermática pós-descongelamento (Salamon, 1973; Fazano, 1986). Embora espermatozóides ejaculados sejam mais sensíveis ao congelamento do que os epididimários (Berger e Clegg, 1985), ainda não foi comprovado se essa maior sensibilidade depende, exclusivamente, do contato com o PS (Rath e Niemann, 1997). Apesar de não se saber, exatamente, quais os fatores que sensibilizam ou promovem a resistência espermática, deve-se considerar a presença de proteínas seminais, que interajam com a membrana plasmática (Moore, Hall e Hibbitt, 1976), assim como a variação na composição do PS entre machos (Pérez-Pé et al., 2001).

Mesmo sabendo-se que em suínos existe uma relação entre as proteínas do PS e a fertilidade dos machos (Ash et al., 1994; Flowers,1997/1998), ainda não é conhecido se esses componentes seminais estão envolvidos na sensibilidade dos espermatozóides ao resfriamento. Assim, este estudo se propõe a verificar um possível efeito do PS na sensibilidade espermática ao resfriamento, a partir da troca cruzada de PS, entre doadores de sêmen com diferente manutenção da motilidade durante a conservação a $17^{\circ} \mathrm{C}$. Como a centrifugação do sêmen é um dos passos necessários para efetuar a troca cruzada de PS, seu efeito sobre a viabilidade espermática também foi avaliado.

\section{Material e métodos}

Foram utilizados como doadores de sêmen cinco machos selecionados a partir da avaliação de 30 machos de uma central de inseminação artificial. A escolha foi baseada na motilidade (MOT) de cinco ejaculados de cada macho, coletados a cada duas semanas, e avaliada durante sete dias de armazenamento em diluente BTS (Beltsville Thawing Solution) a $17^{\circ} \mathrm{C}$.

Os machos utilizados apresentaram MOT ${ }^{3} 60 \%$ após 144 horas (menor sensibilidade ao resfriamento - MES) e MOT $<60 \%$ nas 72 horas (maior sensibilidade ao resfriamento MAS). Ejaculados dos machos MAS e MES foram distribuídos em seis tratamentos, com cinco repetições cada.

T1: sêmen de machos MES, procedimento convencional

T2: sêmen de machos MES, centrifugação, adição de PS de machos MES

T3: sêmen de machos MAS, procedimento convencional

T4: sêmen de machos MAS, centrifugação, adição de PS de machos MAS

T5: sêmen de machos MES, centrifugação, adição de PS de machos MAS

T6: sêmen de machos MAS, centrifugação, adição de PS de machos MES

Nos tratamentos T1 e T3, o sêmen dos machos MES e MAS, respectivamente, foram processados de acordo com o protocolo convencional, isto é, foi imediatamente diluído em BTS, em doses de $100 \mathrm{~mL}$, sem ser submetido à centrifugação. Para os outros tratamentos, o PS foi obtido por centrifugação (800g por $10 \mathrm{~min}$ ) dos ejaculados dos machos MES e MAS. O PS obtido após a primeira centrifugação foi novamente centrifugado (1500g por $10 \mathrm{~min}$ ) para remoção dos espermatozóides remanescentes. Imediatamente após a centrifugação, os espermatozóides foram diluídos com BTS, num volume similar ao do PS retirado, processando quatro soluções pré-diluídas (SPDs). Após a determinação da concentração espermática de cada SPD, foram preparadas as doses de sêmen (DSs) homólogas e heterólogas, com a adição de $10 \mathrm{~mL}$ de PS correspondente, e o volume final de $100 \mathrm{~mL}$ foi completado com diluente.

As DSs, contendo três bilhões de espermatozóides, foram avaliadas durante um período de 168 horas de armazenamento in vitro. A avaliação da MOT foi efetuada a cada 24 horas. Os percentuais de acrossomas normais (Pursel, Johnson e Rampacek, 1972) e de membranas íntegras (IM) foram avaliados nas 24, 72, 120 e 168 horas. A MOT foi avaliada entre lâmina e lamínula, em microscópio óptico (100x), a partir de uma alíquota de $1 \mathrm{~mL}$ de sêmen incubada em banho-maria a $37^{\circ} \mathrm{C}$ por 10 minutos. Para a avaliação dos acrossomas com borda apical normal (NAR), uma alíquota de $20 \mu \mathrm{L}$ foi retirada das DSs e diluída em $0,5 \mathrm{~mL}$ de formol citrato a $2,94 \%$. Posteriormente, uma gota do preparado foi avaliada entre lâmina e lamínula em microscópio óptico de contraste de fase $(1000 \mathrm{x})$. Foram examinadas 200 células de cada preparado. A integridade da membrana espermática foi avaliada por coloração com diacetato de carboxifluoresceína (CFDA) e iodeto de propídio (PI), conforme Harrison e Vickers 


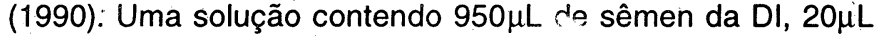
de CFDA (20mM - Calbiochem, Lajolla, CA), $10 \mu \mathrm{L}$ de PI $(7,3 \mu \mathrm{M}$ - Sigma Chemical Co., Deisenhofen) e $20 \mu \mathrm{L}$ de paraformaldeído $(1,7 \mathrm{mM})$ foi incubada a $30^{\circ} \mathrm{C}$ durante oito minutos. Após a incubação, uma alíquota de $4 \mu \mathrm{L}$ foi avaliada, entre lâmina e lamínula, em microscópio de epifluorescência (filtro $E X / D M / B F=450-490 / 510 / 520 \mathrm{~nm}$ ). Foram analisadas 200 células espermáticas por amostra, sendo utilizados os critérios de Ortman e Rodriguez-Martinez (1994) para a contagem das células com membranas íntegras.

Os dados foram analisados pelo procedimento GLM (SAS, 1998), sendo considerados os contrastes de interesse.

\section{Resultados e discussão}

Os resultados da avaliação da MOT e IM são apresentados na Tabela 1. Nela pode-se constatar diferenças significativas $(P=0,038)$ na MOT e na IM $(P=0,027)$, entre os machos MES (T1) e MAS (T3), respectivamente, após um armazenamento de 48 horas e 120 horas, confirmando a diferença desses machos na sensibilidade ao resfriamento.
Espermatozóides oriundos dos machos MAS apresentaram diminuição de $11 \%(P=0,031)$ na MOT nas 24 horas (Tabela 1), após terem sido submetidos à centrifugação (T3 vs T4), sugerindo que eles sejam mais sensíveis que os espermatozóides oriundos dos machos MES, os quais apresentaram diminuição de $16 \%$ na MOT $(P=0,054)$, somente nas 168 horas (T1 vs T2). O efeito prejudicial da centrifugação sobre a MOT é reforçado quando os ejaculados submetidos à centrifugação foram agrupados e comparados aos que não foram submetidos, dentro de cada grupo de machos. O efeito da centrifugação, para os machos MAS, aparece apenas nas 24 horas, provavelmente porque, após este momento, a MOT desses machos já está baixa, devido à sua maior sensibilidade ao resfriamento, não sendo possivel detectar efeitos adicionais da centrifugação.

Com relação à sensibilidade do espermatozóide suíno à centrifugação, os estudos são escassos e contraditórios. Fazano (1986), comparando a realização de duas centrifugações $(800 \mathrm{~g}$ por $10 \mathrm{~min}$ ) com a realização de uma única, durante o processo de congelamento, não observou diferenças na MOT pós-descongelamento. Contudo, Salamon (1973), utilizando velocidade superior $(1.000 \mathrm{~g}$ por $10 \mathrm{~min})$ à

Tabela 1: Motilidade (MOT) e integridade de membrana (IM) de espermatozóides (sptz) de machos suínos menos (MES) ou mais (MAS) sensíveis ao resfriamento a $17^{\circ} \mathrm{C}$, na presença de plasma seminal (PS) homólogo ou heterólogo (média \pm desvio-padrão)

\begin{tabular}{|c|c|c|c|c|c|c|c|c|c|c|c|}
\hline \multirow[b]{2}{*}{ Tratamentos } & \multicolumn{7}{|c|}{ Momento de avaliação da MOT (h) } & \multicolumn{4}{|c|}{ Momento de avaliação da IM (h) } \\
\hline & 24 & 48 & 72 & 96 & 120 & 144 & 168 & 24 & 72 & 120 & 168 \\
\hline T1 (sptz MES + PS MES) & $89 \pm 4$ & $87 \pm 4$ & $85 \pm 5$ & $81 \pm 6$ & $73 \pm 9$ & $63 \pm 18$ & $50 \pm 20$ & $79 \pm 6$ & $73 \pm 12$ & $69 \pm 11$ & $60 \pm 14$ \\
\hline T2 (sptz MES + PS MES) & $88 \pm 3$ & $87 \pm 3$ & $84 \pm 4$ & $74 \pm 16$ & $59 \pm 32$ & $52 \pm 32$ & $34 \pm 29$ & $80 \pm 8$ & $69 \pm 8$ & $64 \pm 17$ & $40 \pm 22$ \\
\hline T3 (sptz MAS + PS MAS) & $87 \pm 7$ & $68 \pm 31$ & $58 \pm 34$ & $36 \pm 40$ & $27 \pm 41$ & $24 \pm 37$ & $18 \pm 29$ & $85 \pm 9$ & $71 \pm 9$ & $51 \pm 9$ & $49 \pm 17$ \\
\hline T4 (sptz MAS + PS MAS) & $76 \pm 11$ & $48 \pm 34$ & $41 \pm 35$ & $26 \pm 29$ & $7 \pm 16$ & $1 \pm 2$ & $0 \pm 0$ & $83 \pm 4$ & $63 \pm 12$ & $39 \pm 21$ & $31 \pm 6$ \\
\hline T5 (sptz MES + PS MAS) & $89 \pm 4$ & $83 \pm 14$ & $75 \pm 21$ & $65 \pm 29$ & $40 \pm 38$ & $35 \pm 37$ & $28 \pm 33$ & $78 \pm 10$ & $67 \pm 14$ & $54 \pm 16$ & $43 \pm 20$ \\
\hline T6 (sptz MAS + PS MES) & $\nabla 8 \pm 16$ & $58 \pm 32$ & $44 \pm 32$ & $25 \pm 32$ & $12 \pm 27$ & $6 \pm 18$ & $1 \pm 2$ & $78 \pm 6$ & $58 \pm 20$ & $42 \pm 20$ & $25 \pm 17$ \\
\hline $\mathrm{T} 2+\mathrm{T} 5$ & $88 \pm 3$ & $84 \pm 11$ & $79 \pm 16$ & $\cdot 69 \pm 24$ & $50 \pm 36$ & $44 \pm 3$ & $31 \pm 30$ & $79 \pm 9$ & $68 \pm 11$ & $59 \pm 17$ & $42 \pm 21$ \\
\hline $\mathrm{T} 4+\mathrm{T} 6$ & $78 \pm 14$ & $54 \pm 32$ & $43 \pm 32$ & $25 \pm 31$ & $11 \pm 24^{\circ}$ & $5 \pm 16$ & $0 \pm 1$ & $79 \pm 6$ & $59 \pm 18$ & $43 \pm 20$ & $27 \pm 15$ \\
\hline Contrastes & \multicolumn{11}{|c|}{ Nivel de significância } \\
\hline $\mathrm{T} 1$ vs $\mathrm{T} 2$ & 0,757 & 0,963 & 0,966 & 0,467 & 0,183 & 0,272 & 0,054 & 0,687 & 0,322 & 0,355 & 0,001 \\
\hline T1 vs T3 & 0,602 & 0,038 & 0,007 & 0,0003 & 0,001 & 0,004 & 0,005 & 0,104 & 0,656 & 0,027 & 0,178 \\
\hline T2 vs T5 & 0,757 & 0,493 & 0,216 & 0,276 & 0,071 & 0,073 & 0,423 & 0,414 & 0,632 & 0,122 & 0,673 \\
\hline T3 vs T4 & 0,031 & 0,076 & 0,164 & 0,476 & 0,235 & 0,141 . & 0,172 & 0,601 & 0,283 & 0,251 & 0,056 \\
\hline T4 vs T6 & 0,517 & 0,276 & 0,721 & 0,966 & 0,700 & 0,674 & 0,931 & 0,214 & $0 ; 396$ & 0,710 & 0,453 \\
\hline$(\mathrm{T} 2+\mathrm{T} 5)$ vs $(\mathrm{T} 1)$ & 0,858 & 0,731 & 0,443 & 0,144 & 0,011 & 0,023 & 0,008 & 0,994 & 0,157 & 0,052 & 0,0004 \\
\hline (T4 + T6) vs (T3) & 0,021 & 0,106 & 0,130 & 0,373 & 0,209 & 0,114 & 0,106 & 0,207 & 0,084 & 0,225 & 0,008 \\
\hline
\end{tabular}

MES: machos com MOT $\geq 60 \%$ nas 144 horas.

MAS: machos com MOT $<60 \%$ nas 72 horas.

T1 e T3 sem centrifugação; T2 e T4 com centrifugação e adição de PS homólogo; T5 e T6 com centrifugação e adição de PS heterólogo

Apesar de, no presente estudo, terem sido verificados altos valores de NAR, com percentuais acima de $85 \%$, e que as diferenças observadas entre T3 e T4 e entre T4 e T6 foram. muito baixas, respectivamente 5,7 e $5,4 \%$, foram verificadas reduções significativas para machos MAS, embora somente nas 72 horas, quando o sêmen desses machos foi submetido à centrifugação e adição de PS homólogo ou heterólogo. do presente estudo, verificou um efeito deletério da centrifugação sobre a MOT. No presente estudo observouse que, tanto para os machos MES (T2 + T5 vs T1) como para os MAS (T4 + T6 vs T1), a centrifugação do sêmen homólogo ou heterólogo provocava uma diminuição da IM $(P<0,01)$, embora somente após 168 horas de armazenamento (Tabela 1). 
Não foram observadas alterações na MOT e na IM (Tabela 1), quando foi efetuada a troca de PS entre os machos MES e MAS, sugerindo que a exposição de espermatozóides ejaculados, ao PS heterólogo, não consegue modificar a sensibilidade ao resfriamento. Sandoval et al. (1991) também não conseguiram reverter a sensibilidade ao choque térmico e ao congelamento de espermatozóides suínos, quando foi efetuada a troca de PS entre o sêmen de machos previamente selecionados como de boa e de má congelabilidade. Thérien, Moreau e Manjunath (1998) sugerem que; logo após a ejaculação, proteínas do PS bovino aderem-se aos espermatozóides, alterando a estabilidade da membrana. Desta forma, a utilização de procedimentos simples, como a lavagem dos espermatozóides, pode não ser eficiente para a remoção dos componentes seminais, aderidos à membrana plasmática, comprometendo tentativas posteriores de ligação de componentes de outro. PS adicionado (Strzezek et al., 1995; Henault e Killian, 1996). Além disto, Henault e Killian (1996) observaram que o PS de machos de baixa fertilidade contém fatores inibidores da fertilidade, aparentemente mais difíceis de serem removidos do que os fatores presentes nos touros de alta fertilidade. No presente estudo, o efeito do PS sobre a MOT e IM foi mais evidente, embora não significativo, quando os espermatozóides dos machos menos sensiveis ao resfriamento foram expostos ao PS dos machos mais sensíveis (Tabela 1). Metz, Berger e Clegg (1990) verificaram que espermatozóides oriundos de ejaculados de baixa MOT (30 a 50\%) apresentaram uma menor capacidade de adsorção de proteínas do PS $(3 \mathrm{pg})$ quando comparados aos espermatozóides de ejaculados com 50 a $70 \%$ de MOT (14 pg). O conjunto dessas observações sugere que a maior ou menor sensibilidade dos éspermatozóides ao resfriamento possa estar relacionada com a sua capacidade de adsorção ou de remoção de fatores associados à viabilidade espermática, presentes no PS.

A constatação da ausência de reversão da sensibilidade da célula espermática ao resfriamento também pode estar relacionada com a concentração de PS empregada. No presente estudo, foi utilizada uma concentração de $10 \%$ de PS. Apesar de Maxwell, Welch e Johnson (1997), empregando a mesma concentração, verificarem melhora na motilidade de espermatozóides submetidos a grandes taxas de diluição, se considerarmos a dificuldade de reversão da ligação dos componentes do PS à membrana espermática, é possível que uma concentração de PS superior aos $10 \%$ seja necessária para alterar a sensibilidade ao resfriamento, como em Knüppel (2000) que, com a adição de $20 \%$ de PS, verificou

\section{Referências}

ASH, K.L.; BERGER, T.; HORNER, C.M.; FAMULA, T.R. Boar sperm plasma membrane protein profile: correlation with the zona-free hamster ova assay. Theriogenology, v. 42, p. 1.217-1.226, 1994.

AURICH, J.E.; KÜHNE, A.; HOPPE, H.; AURICH, C. Seminal plasma affects membrane integrity and motility of equine spermatozoa after cryopreservation. Theriogenology, v. 46, p. 791-797, 1996.

BARRIOS, B.; PÉREZ-PÉ, R.; GALLEGO, M.; TATO, A.; OSADA, J.; MUIÑO-BLANCO, T.; CEBRIÁN-PÉREZ, J.A. Seminal plasma proteins revert the cold-shock damage on ram sperm membrane. Biology of Reproduction, v. 63, p. 1.531-1.537, 2000. melhora na motilidade após teste de termorresistência de sêmen suíno resfriado e armazenado por 24 horas. Melhora na motilidade e na integridade de membrana também foi obtida na espécie eqüina, quando em ejaculados de garanhões com baixa motilidade pós-descongelamento, foi efetuada a adição de $30 \%$ de PS de garanhões com alta motilidade pósdescongelamento (Aurich et al., 1996).

A dominância de determinados machos suínos, em relação a outros, na paternidade dos leitões, após fecundações heterospérmicas, pode estar relacionada com o maior periodo de sobrevivência in vivo dos seus espermatozóides (Flowers, Siggens e McLaren, 1996) e deve-se, ao menos em parte, a um efeito do PS, uma vez que o número de leitões oriundos de um macho não-dominante foi maior quando os seus espermatozóides foram misturados com o PS de um macho dominante (Flowers, 1997). Em estudos posteriores, correlações foram verificadas, entre a concentração de duas proteínas específicas do PS e as taxas de penetração in vitro e a paternidade das leitegadas, após inseminações heterospérmicas (Flowers, 1998). Embora essas observações evidenciem o efeito do PS sobre a fertilidade, ainda não foi comprovado, na espécie suína, que os componentes do PS possam estar envolvidos com a sensibilidade da célula espermática ao resfriamento. Na espécie ovina, foi demonstrado que a adsorção de proteínas do PS revertem (Barrios et al., 2000) ou evitam (Pérez-Pé, CébriánPérez e Muiño-Blanco, 2001) os danos na integridade da membrana espermática, causados pelo choque térmico. Assim, é provável que a variabilidade dos machos, em termos de sensibilidade espermática ao resfriamento, possa estar relacionada com a presença, ausência ou variação na concentração de determinadas proteínas protetoras presentes no PS. Mais estudos são necessários para verificar se proteínas semelhantes às detectadas na espécie ovina estão também presentes nos suínos. Além disso, seria importante determinar qual a concentração do PS, ou de substâncias protetoras presentes no mesmo, necessária para a ocorrência de efeito benéfico.

\section{Conclusões}

Não foi possível reverter a maior sensibilidade ao resfriamento de espermatozóides suínos, após a ejaculação, com a adição de $10 \%$ do PS de machos com menor sensibilidade. A centrifugação utilizada durante o processamento para a troca do PS, entre machos com diferente sensibilidade ao resfriamento, teve efeitos deletérios sobre a motilidade e a integridade de membrana da célula espermática, sobretudo para os machos com maior sensibilidade ao resfriamento.

BERGER, T.; CLEGG, E.D. Effect of male accessory gland secretions on sensitivity of porcine sperm acrosomes to cold shock, initiation of motility and loss of cytoplasmic droplets. Journal of Animal Science, v. 60, p. 1.295-1.302, 1985.

FAZANO, F.A. T. Zur Kryokonservierung von Ebersperma; verschiedene Verfahren zur Samenbehandlung und unterschiedliche Konfektionierungsmethoden unter besonderer Berücksichtigung der Einfriergeschwindigkeit. 1986.89 p. Tese (Doutorado)-Escola Superior de Hannover - Alemanha, 1986.

FLOWERS, W.L.; SIGGENS, K.; McLAREN, D.G. Paternity of pigs from sows bred with combinations of natural service (NS) and Al. Journal of Animal Science, v. 74, p. 223, 1996. 
FLOWERS, W.L. Management of boars for efficient semen production. Journal of Reproduction and Fertility, Suppleınent 52, p. 67-78, 1997. FLOWERS, W.L. Boar fertility and artificial insemination. In: INTERNATIONAL-PIG VETERINARY SOCIETY, 15., 1998, BirminghamEngland. Proceedings...; 1998. p. 45-52.

GUTHRIE, H.D.; MAXWELL, W.M.C.; JOHNSON, L.A. The effect of seminal plasma and dilution rate on the motility and viability of frozen-thawed boar sperm. In: INTERNATIONAL CONGRESS ONANIMALREPRODUCTION, 14., 2000, Estolcomo-Suécia. Abstracts..., 2000. 310 p. p. 143.

HARRISON, R.A.P.; VICKERS, S.E. Use of fluorescence probes to assess membrane integrity in mammalian spermatozoa. Journal of Reproduction and Fertility, v. 88, p. 343-352, 1990.

HENAULT, M.A.; KILIAN, G.J. Effect of homologous and heterologous seminal plasma on the fertilizing ability of ejaculated bull spermatozoa assessed by penetration of zona-free bovine oocytes. Journal of Reproduction and Fertility, v. 108, p. 199-204, 1996.

IWAMOTO, T.; TSANG, A.; LUTERMAN, M.;DICKSON, J.; LAMIRANDE, E.; OKUNO, M.; MOHRI, H.; GAGNON, C. Purification and characterization of a sperm motility-dynein ATPase inhibitor from boar seminal plasma. Molecular Reproduction and Development, v. 31, p. 55-62, 1992.

KNÜPPEL, M. Einflub von Seminalplasma- und BSA-Zusatz in konserviertem Ebersperma auf die Spermienmotilität und Befruchtungsleistung. 2000.95 p. Tese (Doutorado)-Escola Superior de Hannover - Alemanha, 2000.

KORDAN, W.; HOLODY, D.; ERIKSSON, B.; FRASER, L.; RODRIGUEZMARTINEZ, H.; STRZEZEK, J. Sperm motility inhibiting factor (SMIF) - a plasmatic peptide with multifunctional biochemical effects on boar spermatozoa. Reproduction in Domestic Animals, v. 33, p. 347-354, 1998.

MAXWELL, W.M.C.; WELCH, G.R.; JOHNSON, L.A. Viability and membrane integrity of spermatozoa after dilution and flow cytometric sorting in the presence or absence of seminal plasma. Reproduction Fertility Development, v. 8, p. 1.165-1.178, 1997.

METZ, K.W.; BERGER, T.; CLEGG, E.D. Adsorption of seminal plasma proteins by boar spermatozoa. Theriogenology, v. 34, n. 4, p. 691-700, 1990.

MOORE, H.D.M.; HALL, G.A.; HIBBITT, K.G.; Seminal plasma proteins and the reaction of spermatozoa from intact boars and from boars without seminal vesicles to cooling. Journal of Reproduction and Fertility, v. 47, p.3 9-45, 1976.
ORTMAN, K; RODRIGUEZ-MARTINEZ, H. Membrane damage during dilution, cooling and freezing-thawing of boar spermatozoa packaged in plastic bags. Journal of Veterinary Medicine, v. 41, p. 37-47, 1994. PÉREZ-PÉ, R.;BARRIOS, B.; MUINOO-BLANCO, T; CÉBRIAN-PÉREZ, J.A. Seasonal differences in ram seminal plasma revealed by partition in an aqueous two-phase system. Journal of Chromatography B, v. 760, p. 113-121, 2001.

PÉREZ-PÉ, R.; CÉBRIAN-PÉREZ, J.A.; MUIÑO-BLANCO, T. Semen plasma proteins prevent cold-shock membrane damage to ram spermatozoa. Theriogenology, v. 56, p. 425-434, 2001.

PURSEL, V.G.; JOHNSON, L.A.; RAMPACEK, G.B. Acrosome morphology of boar spermatozoa incubated before cold shock. Journal of Animal Science, v. 34, n. 2, p. 278-283, 1972.

PURSEL, V.G.; JOHNSON, L.A.; SCHULMAN, L.L. Effect of dilution, seminal plasma and incubation period on cold shock susceptibility of boar spermatozoa. Journal of Animal Science, v. 37, p. 528-531, 1973.

RATH, D.; NIEMANN, H. In vitro fertilization of porcine oocytes with fresh and frozen-thawed ejaculated or frozen-thawed epididymal semen obtained from identical boars. Theriogenology, v. 47, p. 785793, 1997.

SALAMON, S. Deep freezing of boar semen. III Effects of centrifugation, diluent and dilution rate, pellet volume, and method of thawing on survival of spermatozoa. Australian Journal of Biological Science, v. 26, p. 239-247, 1973.

SANDOVAL, J.L.; SCHEID, I.R.; BARIONI JR., W; MIES FILHO, A.; MARIANO, M.S. Effect of homologous and heterologous seminal plasma on boar sperm following cold shock or deep freezing. Reproduction in Domestic Animals, Supplement 1, p. 393, 1991.

SAS Institute (Cary NC) SAS user's guide. Statistical Analysis System, Release 6.12, 1998.

STRZEZEK, J., TORSKA, J., BORKOWSKI, K., GLOGOWSKI, J., WYSOCKI, P., HOLODY, D. The biochemical characteristics of boar seminal plasma during high ejaculation frequency. Reproduction in Domestic Animals, v. 30, p. 77-84, 1995.

THÉRIEN, I; MOREAU, R.; MANJUNATH, P. Major proteins of bovine seminal plasma and high-density lipoprotein induce cholesterol efflux from epididymal sperm. Biology of Reproduction, v. 59, p .768-776, 1998. 